\title{
An E. coli biosensor for screening of CDNA libraries for isochorismate pyruvate lyase-encoding cDNAs
}

\author{
Yingjie Zhou $^{1}$ - Johan Memelink ${ }^{1} \cdot$ Huub J. M. Linthorst ${ }^{1}$
}

Received: 29 November 2017 / Accepted: 17 May 2018 / Published online: 23 May 2018

(c) The Author(s) 2018

\begin{abstract}
Salicylic acid (SA) is an essential hormone for development and induced defense against biotrophic pathogens in plants. The formation of SA mainly derives from chorismate via demonstrated isochorismate synthase (ICS) and presumed isochorismate pyruvate lyase (IPL)-mediated steps in Arabidopsis thaliana, but so far no plant enzyme displaying IPL activity has been identified. Here, we developed an E. coli SA biosensor to screen for IPL activity based on the SalR regulator/salA promoter combination from Acinetobacter sp ADP1, to control the expression of the reporter luxCDABE. The biosensor was responsive to micromolar concentrations of exogenous SA, and to endogenous SA produced after transformation with a plasmid permitting IPTG-inducible expression of bacterial IPL in this biosensor strain. After screening a cDNA library constructed from turnip crinkle virus (TCV)-infected Arabidopsis ecotype Di-17, we identified an enzyme, PRXR1, as a putative IPL that converts isochorismate into SA. Our results provide a new experimental approach to identify IPL and new insights into the SA biosynthesis pathway in Arabidopsis.
\end{abstract}

Keywords Salicylic acid $\cdot$ Isochorismate pyruvate lyase $\cdot$ Screening $\cdot$ Arabidopsis thaliana

\section{Introduction}

Salicylic acid (SA) is a small phenolic compound present in plants and bacteria. In plants, SA is an essential signaling molecule that mediates defense against infections with biotrophic pathogens and is produced to regulate several physiological functions, including flowering induction and seed germination (Rivas-San Vicente and Plasencia 2011; Spoel and Dong 2012). SA functions as a precursor of siderophores in many bacteria, such as pyochelin in Pseudomonas aeruginosa, yersiniabactin in Yersinia pestis and $Y$. enterocolitica, and mycobactin in Mycobacterium tuberculosis (Cox et al. 1981; Crosa and Walsh 2002; Gaille et al. 2003; Pelludat and Brem 2003). The SA biosynthesis pathway in bacteria

Communicated by S. Hohmann.

Electronic supplementary material The online version of this article (https://doi.org/10.1007/s00438-018-1450-5) contains supplementary material, which is available to authorized users.

Huub J. M. Linthorst

hulint@gmail.com

1 Institute of Biology, Leiden University, P.O. Box 9505, 2300 RA Leiden, The Netherlands is well known. Chorismate, the end product of the shikimate pathway, is converted to SA by two enzymes: isochorismate synthase (ICS) and isochorismate pyruvate lyase (IPL), encoded in $P$. aeruginos $a$ by the genes $p c h A$ and $p c h B$, and in $P$. fluorescens by the genes pmsA and pmsB (MercadoBlanco et al. 2001; Gaille et al. 2002). In Y. enterocolitica and M. tuberculosis, salicylate synthase (Irp9 and MbtI, respectively) carries out the direct conversion of chorismate to salicylate (Kerbarh et al. 2005; Zwahlen et al. 2007). SA biosynthesis in plants also originates from chorismate, but here two different pathways have been suggested. However, neither of these branches has been conclusively elaborated (Dempsey et al. 2011; Boatwright and Pajerowska-Mukhtar 2013; Dempsey and Klessig 2017).

The first branch involves the enzyme phenylalanine ammonia-lyase (PAL) which converts phenylalanine to cinnamic acid. The second pathway is dependent on ICS, which catalyzes the conversion of chorismate to isochorismate (Wildermuth et al. 2001; Strawn et al. 2007; Garcion et al. 2008). The reaction leading to SA is expected to involve an as of yet unidentified IPL enzyme (Macaulay et al. 2017). Due to the chloroplast localization of ICS in plants and the fact that transgenic Arabidopsis overexpressing the bacterial $N a h G$ (salicylate hydroxylase) gene 
in the chloroplasts failed to accumulate SA after pathogen infection or UV exposure (a stimulus for SA accumulation), this pathway is likely to be localized in the chloroplasts (Nawrath et al. 2002; Garcion et al. 2008; Fragnire et al. 2011). The contribution of the isochorismate pathway for SA biosynthesis differs depending on the plant species. For instance, the isochorismate biosynthesis pathway contributes more than $90 \%$ of the SA produced during pathogenesis in Arabidopsis, while the PAL and IC pathways are equally important for pathogen-induced SA biosynthesis in soybean (Garcion et al. 2008; Shine et al. 2016).

Conventional methods of SA quantification in plant tissues are based on high-performance liquid chromatography (HPLC) or gas chromatography/mass spectrometry (GC/ MS), which required time-consuming extraction steps with organic solvents (Nawrath and Métraux 1999; Verberne et al. 2000; Huang et al. 2006; Garcion et al. 2008). Given the importance of SA, salicylate-responsive biosensors were designed to detect SA and SA derivatives faster and for larger scale sample ranges (Huang et al. 2005; Shin 2010). Huang et al. (2005) engineered an Acinetobacter biosensor originating from Acinetobacter baylyi sp. ADP1. This strain is able to use SA as sole carbon source (Jones et al. 2000). It contains the salA operon encoding salicylate hydroxylase involved in SA degradation to catechol. Transcription of this operon is activated in the presence of SA that interacts with the regulatory protein SalR. SalR belongs to the LysRtype transcriptional regulator (LTTR) family of proteins that contain two typical major domains, i.e. an $\mathrm{N}$-terminal helix-turn-helix motif (residues 18-47) and a C-terminal co-factor binding domain. SalR activates the transcription of salA though binding to a dyadic sequence (TTCA-N ${ }_{12}-$ TGAT) around - $190 \mathrm{bp}$ upstream of the salA transcription start site, in response to the inducer SA (Schell 1993; Jones et al. 2000). For the construction of the Acinetobacter biosensor, the luxCDABE operon from Photorhabdus luminescens, encoding luciferase and enzymes involved in biosynthesis of its substrate (Winson et al. 1998a, b) was integrated into the Acinetobacter genome, resulting in Acinetobacter strain ADPWH_lux. This biosensor is highly sensitive to SA, methyl-SA, and acetyl-SA, and has been used to monitor SA in plant tissues (Huang et al. 2006; DeFraia et al. 2008; Ding et al. 2014).

Large-scale genetic screens for mutants in Arabidopsis with reduced SA accumulation after pathogen infection have resulted in identification of the gene EDS5 encoding a chloroplast-localized MATE (multidrug and toxin extrusion) transporter shown to transport SA from the chloroplast to the cytosol, and in the identification of the gene encoding the SA biosynthetic enzyme ICS1 (Nawrath and Métraux 1999; Dewdney et al. 2000; Serrano et al. 2013). For years, biologists have looked for an enzyme with IPL activity in plants to complete the ICS branch in the SA biosynthesis pathway, but as of yet no such activity was found.

In this article, we describe the construction and characterization of a plasmid-based E. coli SA biosensor to screen a cDNA library of Arabidopsis for genes encoding the unidentified IPL. The sensing components, including the SA-inducible promoter PsalA, the reporter operon luxCD$A B E$ and the salR gene encoding the LysR-type regulator of salA, were subcloned from Acinetobacter ADPWH_lux into a plasmid vector. As proof of principle, an expression plasmid was constructed carrying the $p m s B$ gene from $P$. fluorescens encoding bacterial IPL behind the IPTG-inducible lac promoter, which served as a positive control for the biosensor. Since $E$. coli contains the entC gene encoding ICS that supports the production of isochorismate, transformation with the $p m s B$ plasmid resulted in synthesis of SA, which activated the SalR regulator, leading to expression of the lux genes and generation of light. This made it possible to use the E. coli biosensor strain to screen a cDNA expression library for cDNAs encoding proteins with IPL activity, by determining the light production of individual clones. Based on this approach, we identified PRXR1 as a potential IPL in Arabidopsis.

\section{Results}

\section{Construction of a luminescence reporter plasmid}

Our aim was to engineer a biosensor that could detect endogenous SA in E. coli. In our construct, the promoterless lux$C D A B E$ operon encoding luciferase was cloned behind the upstream promoter region of the salA operon (PsalA) to replace the original salA gene. SA-inducible expression of the resulting promoter-reporter operon is regulated by the product of the salR gene (Jones et al. 2000; Mercado-Blanco et al. 2001) (Fig. 1a). The resulting plasmid containing salR downstream of the newly created PsalA::luxCDABE operon was named pLUX. E. coli XL-1 Blue MRF' cells carrying pLUX (XL1-LUX) were able to produce luminescence due to the constitutive expression of luxCDABE in the presence of exogenous SA and this phenomenon could be easily captured by auto-exposure in the dark (Fig. 1b).

In general, XL1-LUX exhibited increased luciferase expression for concentrations of salicylate between 0 and $500 \mu \mathrm{M}$ when the cells were grown in liquid medium at room temperature $\left(22^{\circ} \mathrm{C}\right)$ and $28^{\circ} \mathrm{C}$ with fourfold and fivefold increased luminescence compared to uninduced cells (Fig. 1c). When incubated at $37{ }^{\circ} \mathrm{C}$, uninduced cells $(0 \mu \mathrm{M}$ SA) had strong basal luminescence that barely changed with higher SA concentrations. When grown on solid medium at room temperature, luminescence responded likewise to increasing SA concentrations (Fig. 1d). These results 
Fig. 1 E. coli-based whole-cell biosensor XL1-LUX induction by SA. a Representation of chromosomally integrated luxCDABE in Acinetobacter sp. ADPWH_lux (Huang et al. 2005) and pLUX reporter cassette. b Selection of E. coli XL1-LUX transformants on LC plate supplemented with SA. The $E$. coli transformant selected for our experiments is indicated by the arrow. Scale bar $=1 \mathrm{~cm}$. c Relative luminescence values from XL1-LUX grown in liquid medium with different concentrations of SA, incubated at different temperatures. Luminescence values of uninduced cells ( $0 \mu \mathrm{M} \mathrm{SA})$ incubated at room temperature $\left(22{ }^{\circ} \mathrm{C}\right)$ were taken as 1 . Error bars represent the mean $\pm \mathrm{SE}$ $(n=3)$. d Luminescence images on X-ray film of XL1-LUX streaked onto solid medium containing different concentrations of SA (a)
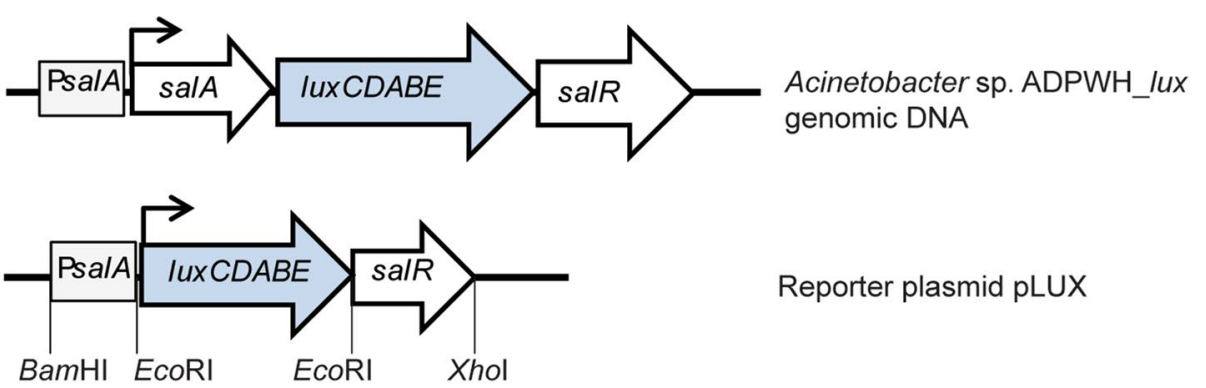

Reporter plasmid pLUX (b)

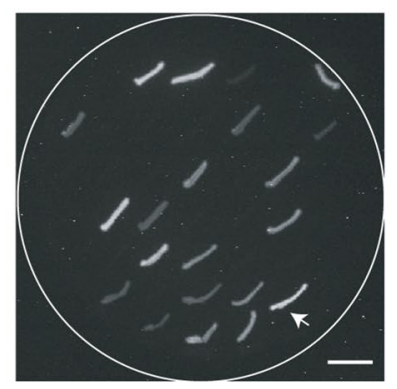

(d)

(c)

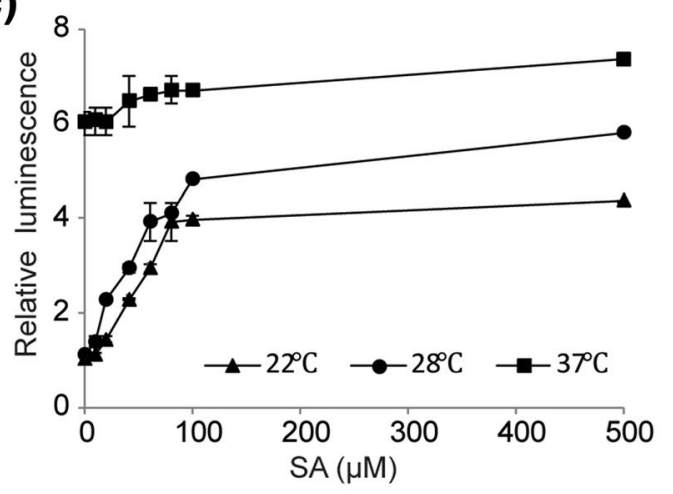

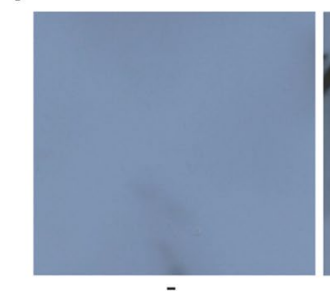

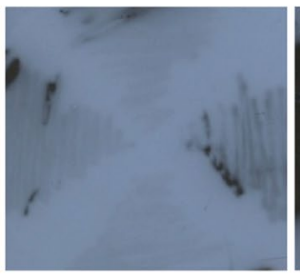

$2 \mu \mathrm{M} S A$

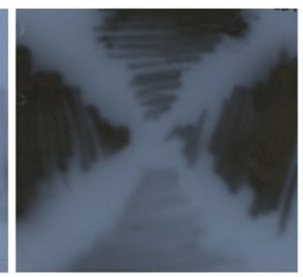

$10 \mu \mathrm{M} \mathrm{SA}$

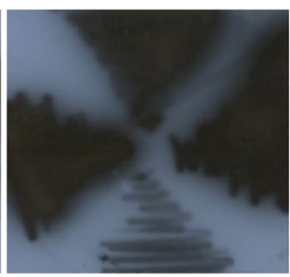

$100 \mu \mathrm{M}$ SA indicated that the XL1-LUX biosensor was capable of detecting exogenous SA with a useful dose-response relationship at lower growth temperatures.

\section{Endogenous SA generation and luminescence monitoring}

In E. coli, isochorismate synthase EntC transforms chorismate into isochorismate, which provides substrate for enterobactin biosynthesis (Ozenberger et al. 1989; Walsh et al. 1990). PmsB, originally from P. fluorescens, can convert the endogenous isochorismate into SA when expressed in E. coli (Mercado-Blanco et al. 2001; Zhou 2018). In order to test whether XL1-LUX is able to respond to endogenous SA, a pBK-CMV plasmid derivative carrying the $p m s B$ gene under the control of the strong isopropyl thio$\beta$-D-galactoside (IPTG)-inducible lac promoter (pBKCMV-pmsB), was transformed into XL1-LUX (Fig. 2). As
Fig. 2 E. coli-based biosensor XL1-LUX monitoring endogenous SA. Images of luminescence of XL1-LUX containing empty pBK-CMV or pBK-CMV-pmsB in the absence $(-)$ or presence of IPTG (+). Luminescence of XL1-LUX with empty vector in the presence of $100 \mu \mathrm{M}$ SA was included as a control

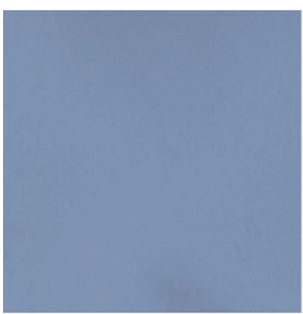

Empty vector(+)

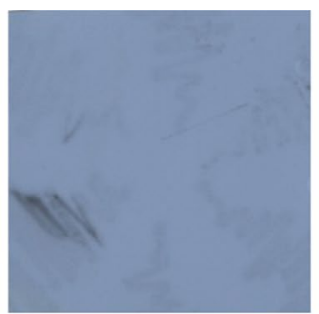

pmsB (-)

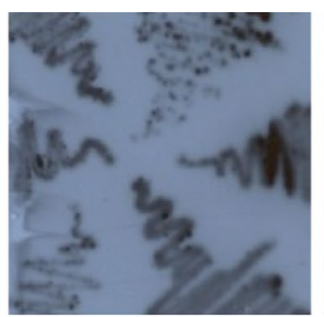

pmsB (+)

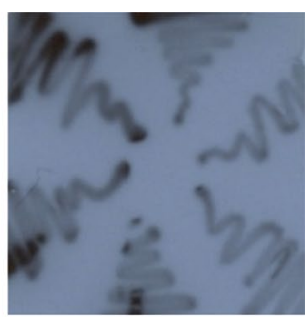

Empty vector $(100 \mu \mathrm{M}$ SA) 
a negative control, a pBK-CMV vector without insertion was transformed into XL1-LUX. We observed stronger luminescence in the cells containing the expressed PmsB compared to the negative control and the uninduced cells (Fig. 2). This result indicated that $E$. coli XL1-LUX was sensitive to the endogenously produced SA.

\section{Arabidopsis cDNA library screening using XL1-LUX}

Previous work showed that inoculation of turnip crinkle virus (TCV) on the resistant Arabidopsis ecotype Dijon (Di-17) results in an increase in SA content, in the development of a hypersensitive response (HR) and in induction of PR gene expression (Uknes et al. 1993; Dempsey et al. 1997; Kachroo et al. 2000; Chandra-Shekara et al. 2006). This indicates that the genes involved in SA biosynthesis are active upon TCV inoculation. To find genes encoding IPL in Arabidopsis using the biosensor, a cDNA plasmid (pBK-CMV) library made from mRNA of Arabidopsis Di-17 leaves infected by TCV (Ausubel et al. 1987; Cooley et al. 2000) was transformed into $E$. coli XL1-LUX. Cells were selected for the presence of both the pLUX and the cDNA plasmid using carbenicillin and kanamycin, respectively (Fig. 3).

One and a half million $E$. coli transformants were screened, resulting in approximately 1000 colonies that were able to generate higher luminescence than the background. Those colonies were recovered and streaked onto fresh medium. From 220 colonies that were selected, the pBK-CMV plasmids were isolated and re-transformed into XL1-LUX. This resulted in 43 clones displaying relatively strong luminescence (Fig. 4). The cDNAs from these clones were sequenced and 12 of them were in frame with the $\beta$-galactosidase $\alpha$-fragment (Table S1).

\section{SA accumulation in $E$. coli expressing candidate cDNAs}

To determine if the candidate cDNAs can direct SA accumulation in $E$. coli, we transformed the corresponding pBK-CMV plasmids into XL1-Blue MRF' and BL21 (DE3) pLysS, a strain that is optimized for high expression
Fig. 3 Schematic representation of cDNA library screening in XL1-LUX. E. coli cells contain the reporter plasmid pLUX and a cDNA-harboring pBK-CMV plasmid. In the presence of IPTG, cells containing a cDNA encoding an enzyme with IPL activity are able to convert endogenous isochorismate to $\mathrm{SA}$, resulting in activation of salR and accumulation of luciferase and its substrates that lead to light production
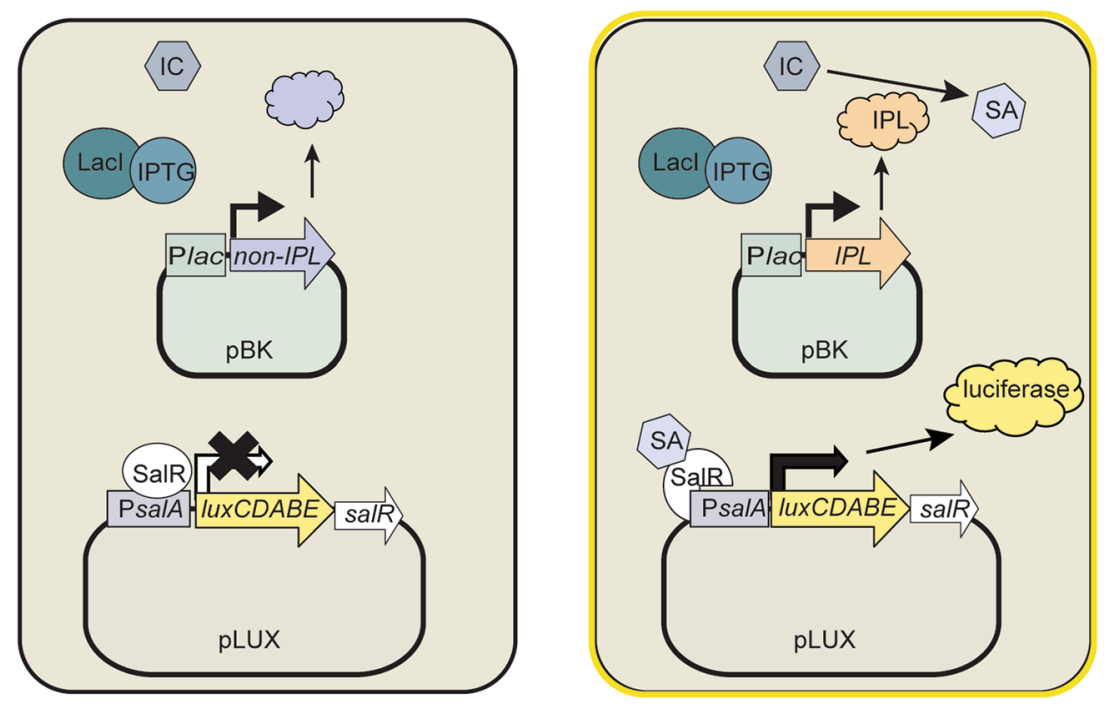

Fig. 4 Luminescence scanner image of a Petri dish containing E. coli colonies from the cDNA library screening. The plate is divided in quadrants with colonies obtained after retransformation of XL1-LUX with four different plasmids (indicated by numbers) picked up in the screening, photographed in the light (left) or dark (right). Scale bar $=1 \mathrm{~cm}$
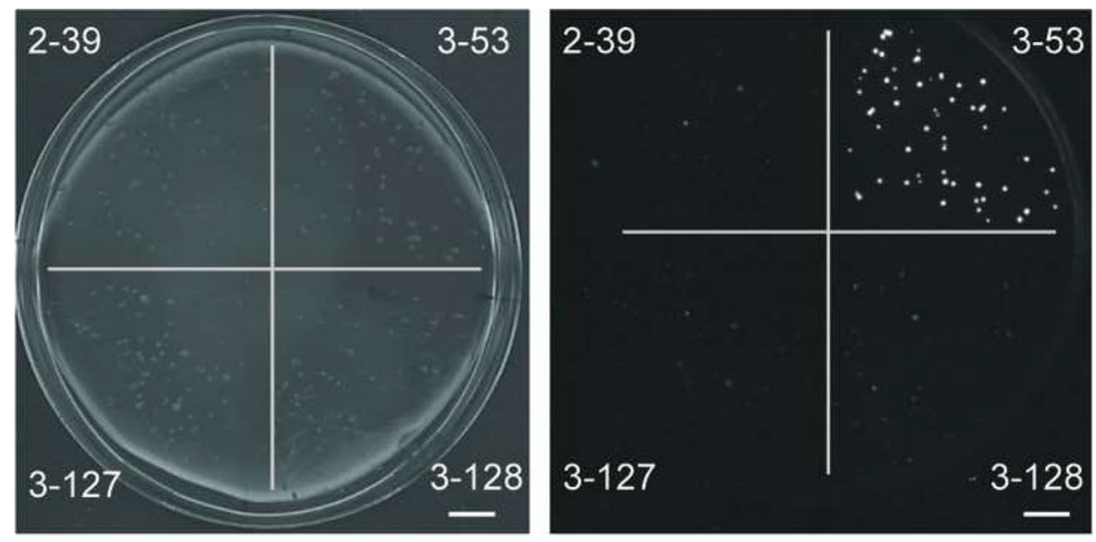
of cloned genes (Fig. 5). The $p m s B$ gene cloned in pBKCMV and pASK-IBA45plus served as positive controls. The positive control extract obtained from XL1-Blue MRF' containing the $p m s B$ gene showed slightly higher luminescence activity than the uninduced control. The crude cell extracts of the candidate strains had no effect on luminescence, suggesting that SA was not produced or produced in such low amounts in these cells that it was not detectable by Acinetobacter (Fig. 5a).

We reasoned that E. coli XL1-Blue MRF' might not produce enough isochorismate to allow sufficiently high production of SA, or that expression of the cDNAs was not sufficiently high in these cells. When crude cell extracts of these cells were incubated with chorismate, together with a crude cell extract of BL21 (DE3) pLysS transformed with an overexpression construct of the bacterial ent $C$ gene encoding isochorismate synthase, the SA production by the control pmsB extract was considerably higher. Of the candidate clones, only clone 3-53 resulted in low, but reproducible levels of SA. Sequencing revealed that the cDNA of plasmid 3-53

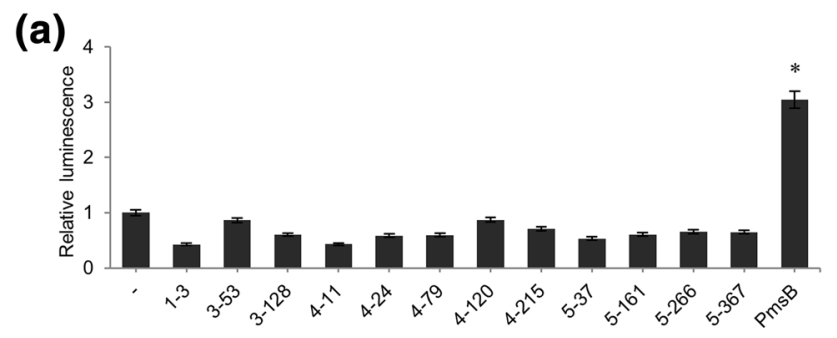

(b)

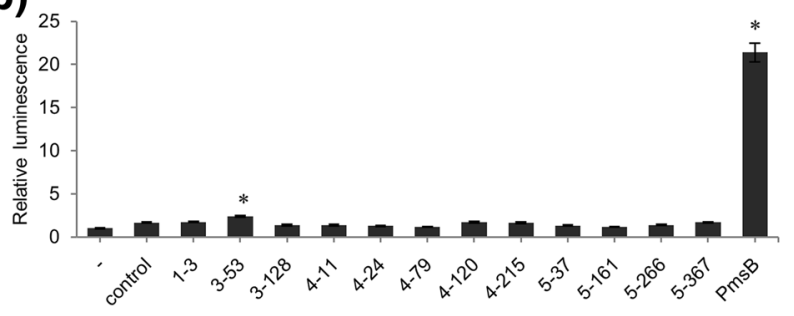

Fig. 5 SA production in crude $E$. coli cell extracts, as measured through the Acinetobacter biosensor. a Luminescence values obtained with crude E. coli cell extracts from IPTG-induced XL1-Blue MRF' containing indicated pBK-CMV plasmids from the screening. "-" indicates uninduced Acinetobacter cells. The asterisk indicates a significant difference in comparison to the uninduced Acinetobacter cells $(P<0.05)$. b Luminescence values obtained with crude $E$. coli cell extracts from IPTG-induced BL21 (DE3) pLysS transformed with the indicated plasmids, crude cell extract from $E n t C$-overexpressing E. coli and incubated for $1 \mathrm{~h}$ with chorismate. "-" indicates non-induced Acinetobacter cells. "control" indicates Acinetobacter cells that were induced by a mixture of crude cell extract from entCoverexpressing $E$. coli and chorismate. Asterisks indicate significant differences in comparison to the control $(P<0.05)$. Luminescence values of uninduced Acinetobacter cells were taken as 1 . Luminescence values were converted to SA concentrations using a standard curve similar to the one shown in Fig. $6 \mathrm{~b}$. Error bars represent the mean $\pm \operatorname{SE}(n=3)$ encodes a peroxidase named PRXR1 (also called ATP1a) (Fig. 5b).

\section{IPL activity of PRXR1}

To establish whether PRXR1 catalyzes the conversion of isochorismate into SA, recombinant His-tagged PRXR1 protein was expressed in E. coli and purified by Ni-NTA agarose chromatography. The molecular subunit mass of HisPRXR1 protein was evaluated by $15 \%$ SDS-PAGE followed by Coomassie Brilliant Blue staining or by Western blot hybridization using anti-His antibodies. As shown in Fig. 6a, a band was visible at the expected position of $38 \mathrm{kDa}$ for the recombinant His-tag-PRXR1 protein. All Coomassie Brilliant Blue-stained bands showed up on the Western blot, indicating that all proteins in the Ni-NTA purified sample were His-tagged PRXR1 and degradation products thereof containing the His-tag. By converting luminescence values to SA concentration using a SA calibration series, the results showed that incubation of chorismate with the combination of the recombinant proteins EntC and His-PRXR1 resulted in enhanced levels of SA, in a His-PRXR1-dependent manner (Fig. 6b). Because isochorismate also spontaneously converted to salicylate (DeClue et al. 2006; Luo et al. 2011), basal amounts of SA were also detected with the combination of chorismate and EntC. Without EntC, incubation of PRXR1 with chorismate also resulted in a slightly higher SA content, possibly because Acinetobacter is likely to contain an ICS gene that could provide low amounts of isochorismate. In the absence of chorismate, PRXR1 alone or with EntC did not produce a SA-related signal. The results indicate that PRXR1 might have IPL activity.

\section{Discussion}

SA is an important plant signaling molecule for defense against biotrophic pathogens and is regulating certain developmental processes. In Arabidopsis, the majority of SA is produced via an ICS-mediated pathway. This pathway involves the conversion of chorismate to isochorismate by the enzyme ICS and isochorismate to SA by the enzyme IPL. ICS has been isolated and has been well-studied. However, evidence for IPL activity in Arabidopsis is still lacking. In this article, we describe an E. coli biosensor that can be used to screen cDNA expression libraries for finding genes encoding proteins with IPL activity. The in vivo screening resulted in the identification of PRXR1, which belongs to the peroxidase family. Increased production of SA from chorismate (in the presence of EntC and PRXR1) in vitro suggests that PRXR1 could indeed have IPL activity.

In this study, we designed a new E. coli SA biosensor instead of the previously described Acinetobacter 


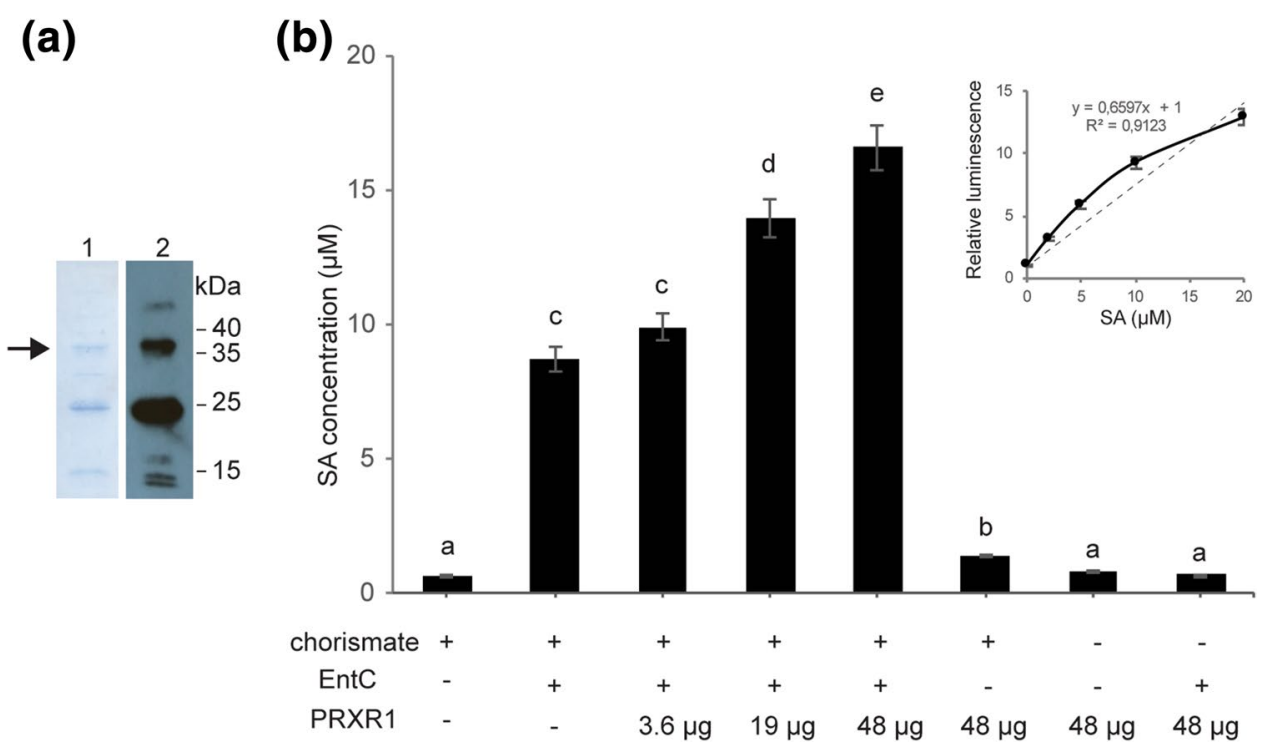

Fig. 6 SA production in vitro with recombinant His-tagged PRXR1. a His-tagged PRXR1 protein was expressed in E. coli, purified and analyzed using SDS-PAGE and either stained with Coomassie Brilliant Blue (lane 1) or visualized with Western blotting using anti-His antibodies (lane 2). The positions of molecular mass markers are indicated in $\mathrm{kDa}$. The arrow indicates the position of the recombinant
PRXR1 protein band. b Production of SA in vitro, as measured with the Acinetobacter biosensor. Letters indicate significantly different groups $(P<0.05)$. Error bars represent the mean $\pm \mathrm{SE}(n=3)$. This experiment was repeated three times with similar results. The inset shows the calibration curve used for converting luminescence values to SA concentrations
ADPWH_lux to screen the Arabidopsis cDNA library. This was necessary because plant protein expression systems for A. ADPWH_lux do not exist. The biosensor module was obtained by PCR from Acinetobacter ADPWH_lux genomic DNA and consisted of the SA-responsive PsalA promoter in front of the lux operon and the constitutively expressed gene salR encoding the regulator protein. These modules were cloned in an E. coli plasmid vector, which after transformation resulted in a functional $E$. coli biosensor for detection of either exogenously supplied SA or intracellularly generated SA.

Our biosensor XL1-LUX was responsive to SA concentrations in the low $\mu \mathrm{M}$ range (above $2 \mu \mathrm{M}$ on solid SA supplied medium), as indicated by detectable luminescence (Fig. 1). It was surprising that the optimum temperature for dynamically detecting a salicylic acid concentration range was found to be $28{ }^{\circ} \mathrm{C}$ or lower, which is lower than the optimum growth temperature for $E$. coli and most Acinetobacter strains. Apart from being an activator of the salA promoter in the presence of SA, SalR was found to be a repressor of the salA operon in the absence of SA (Zhang et al. 2012). We speculate that SalR represses salA gene expression by negative regulation via the binding site (TTCA- ${ }_{12}$-TGAT) in the promoter of salA in Acinetobacter sp. ADP1 (Schell 1993). The induction of luxCDABE by SalR at $37{ }^{\circ} \mathrm{C}$ in the absence of SA suggests that the conformational change that turns SalR from repressor to activator is subject to temperature in E. coli. Compared to when a gene is integrated in the chromosome, the copy number when the gene is present on a plasmid is much higher, which may also account for leaky expression. Moreover, it is possible that in the reconstructed operon, the PsalA promoter functions sub-optimally, or that salR gene expression is lower in E. coli than in Acinetobacter. This would explain our finding that the expression of luxCDABE is activated less efficiently by SalR in $E$. coli than in Acinetobacter, and that $E$. coli cells show some leaky expression under non-induced conditions compared to Acinetobacter at $37^{\circ} \mathrm{C}$. To improve the sensitivity response to SA and decrease the leaky expression of lux, the intergenic region between the SalR binding site and the luxCDABE gene could be modified, for instance, by substitution of an E. coli compatible ribosome binding site, or by altering the SalR binding affinity of PsalA (Park et al. 2005; Blazeck and Alper 2013; Jha et al. 2014).

The sensor was tested for detection of endogenously produced SA after transformation with a plasmid harboring the $P m s B$ gene encoding bacterial IPL. Expression of the lux operon was observed after induction with IPTG, but lowlevel leaky expression of luciferase activity was noticeable in uninduced cells (Fig. 2). We transformed the biosensor with a cDNA plasmid library of TCV-infected Arabidopsis to screen for luminescent clones (Figs. 3, 4). We identified 12 clones that were in frame with the $\beta$-galactosidase $\alpha$-fragment and that were able to activate lux gene expression in $E$. coli, and which we therefore considered to express IPL candidates (Table S1). Subsequent analyses confirmed 
that at least one, PRXR1, might have IPL enzyme activity (Figs. 5, 6).

The isochorismate pathway is at least partly (ICS, EDS5) localized in the chloroplast, which suggests that the hypothetical IPL could also be chloroplast localized. Previous findings by Chong et al. (2015) suggested that PRXR1 interacted with an endoplasmic reticulum (ER)-localized heat-shock protein 90.7 (HSP90.7), which indicates that PRXR1 is possibly localized in the ER. PRXR1 belongs to the group of secretory class III peroxidases (EC 1.11.1.7) only found in plants. These are heme-containing glycoproteins able to oxidize various substrates, utilizing hydrogen peroxide as electron donor. Identified substrates include phenolic compounds, auxin, and secondary metabolites (Welinder et al. 1992; Ruiz-Duenas et al. 2001; Passardi et al. 2004). Together, these results lead to the following model (Fig. 7). We speculate that isochorismate is transported from the chloroplasts to the cytosol by the MATE transporter EDS5, which is essential for accumulation of cytoplasmic SA (Nawrath et al. 2002; Serrano et al. 2013; Yamasaki et al. 2013). Once isochorismate is in the cytosol, PRXR1 may catalyze the conversion of isochorismate to SA. Alternatively, PRXR1 may be re-localized into the chloroplasts to convert isochorismate into SA.

We showed that only a small amount of chorismate was transformed into SA via the combination of EntC and PRXR1, suggesting that the protein assay conditions were not optimal. Alternatively, PRXR1 may play only a minor role in SA biosynthesis, and other enzymes, either chloroplast or cytoplasm localized, are involved in this process as well. Another possibility relies on the fact that isochorismate

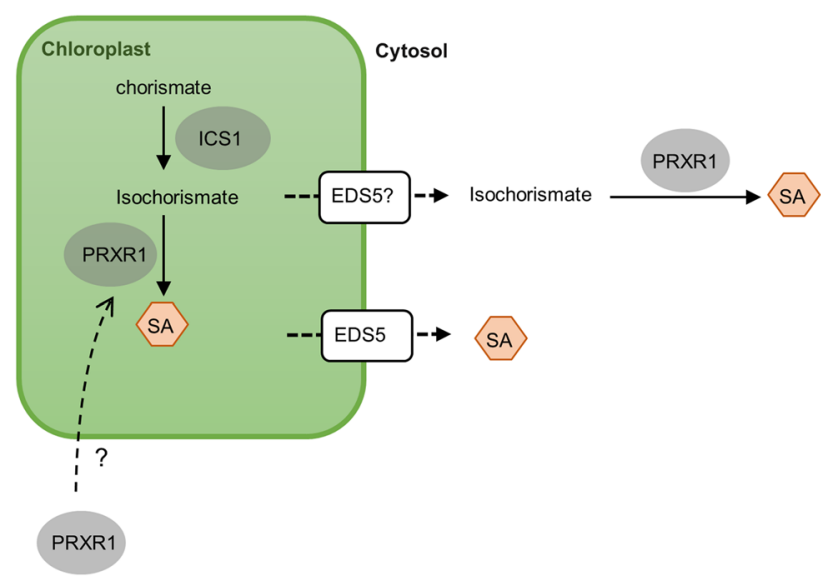

Fig. 7 Proposed model describing the isochorismate-dependent SA biosynthesis pathway in Arabidopsis. ICS1 converts chorismate into isochorismate. Isochorismate is exported from the chloroplasts to the cytosol by EDS5 or other transporters (indicated by question mark) and converted into SA by PRXR1. Alternatively, the formation of $\mathrm{SA}$ is in the chloroplasts. In this case, PRXR1 is re-localized into the chloroplasts and functions as IPL spontaneously undergoes rearrangement to form isoprephenate without enzyme catalysis (DeClue et al. 2006; Luo et al. 2011). This could suggest that isoprephenate in the reaction mixture is converted to SA by PRXR1. In addition, slightly enhanced luminescence was observed in the reaction mixtures containing chorismate and EntC only, implying that a small amount of isochorismate spontaneously converted into SA. Therefore, it could also be possible that PRXR1increased SA production relies on a stabilizing effect of the enzyme on EntC, which would lead to enhanced production of isochorismate and subsequent increased spontaneous conversion to SA.

\section{Materials and methods}

\section{Reporter plasmid construction}

Genomic DNA was isolated from Acinetobacter sp. ADPWH_lux (Huang et al. 2005) with the genomic DNA purification protocol from Cold Spring Harbor (Green and Sambrook 2012). The SalA promoter region, salR with promoter and luxCDABE were amplified from the Acinetobacter sp. ADPWH_lux genomic DNA and cloned into pJET1.2 (Thermo Scientific), using primers shown in Table S2. The salA promoter digested from pJET1.2 with BamHI and EcoRI, introduced upstream of salR in pJET1.2 digested with BamHI and EcoRI to generate plasmid pSALAR. lux$C D A B E$ was excised from pJET1.2 with EcoRI and inserted between the salA promoter and salR region in the pSALAR plasmid, resulting in plasmid pLUX, which was transformed into E. coli strain XL-1 Blue MRF'. Plasmids were selected on carbenicillin $(200 \mu \mathrm{g} / \mathrm{mL})$ and $500 \mu \mathrm{M} \mathrm{SA}$. The plates were photographed in the dark after auto-exposure in a Gel Doc XR + Gel Documentation System (Bio-Rad). The reporter plasmid containing the PsalA::luxCDABE:salR cassette was named pLUX.

\section{Transformation and validation of luciferase expression}

Reporter plasmid pLUX was transformed into $E$. coli XL-1 Blue MRF' cells and grown on LC agar plates containing carbenicillin $(200 \mu \mathrm{g} / \mathrm{mL})$ at room temperature for 3 days. Individual clones were inoculated onto LC agar plates containing carbenicillin $(200 \mu \mathrm{g} / \mathrm{mL})$ and SA at various concentrations ranging from 0 to $100 \mu \mathrm{M}$ and incubated at $28{ }^{\circ} \mathrm{C}$ for 2-3 days. The luminescence was detected using an image scanner (ProXPRESS 2D Proteomic Imaging System, Perkin-Elmer) or X-ray film (Fuji). Competent E. coli XL1-LUX cells were prepared from liquid media containing carbenicillin $(200 \mu \mathrm{g} / \mathrm{ml})$ and grown at room temperature $\left(22^{\circ} \mathrm{C}\right)$ until $\mathrm{OD}_{600}=0.4$, after which the procedure followed the standard 
protocol (Inoue et al. 1990). For SA induction of E. coli XL1-LUX, $50 \mu \mathrm{L}$ of cell cultures $\left(\mathrm{OD}_{600}=0.4\right)$ were mixed with $20 \mu \mathrm{L}$ of various SA concentrations $(0-500 \mu \mathrm{M})$ and $60 \mu \mathrm{L} \mathrm{LC}$ medium, and incubated for $1 \mathrm{~h}$ at room temperature $\left(22{ }^{\circ} \mathrm{C}\right), 28$ and $37^{\circ} \mathrm{C}$, respectively. The luminescence was determined immediately by using a Victor light 1420 luminescence counter (Perkin-Elmer).

\section{Construction of a double plasmid system for sensing endogenous SA in E. coli}

$P m s B$ with His-tag sequence was amplified from $P$. fluorescens, cloned into pBK-CMV and transformed into $E$. coli XL1-LUX and selected on LC agar plates with carbenicillin $(100 \mu \mathrm{g} / \mathrm{mL})$ and kanamycin $(25 \mu \mathrm{g} / \mathrm{mL})$. Individual clones were selected and inoculated on LC agar plates with carbenicillin $(100 \mu \mathrm{g} / \mathrm{mL})$, kanamycin $(25 \mu \mathrm{g} / \mathrm{mL})$ and $1 \mathrm{mM}$ IPTG. The cells were incubated at room temperature for 3-4 days. Luminescence was detected using X-ray film.

\section{CDNA library screening in $E$. coli}

A cDNA library prepared from a mixture of RNAs from 18 days old Arabidopsis ecotype Di-17 leaves harvested at $6,12,19$ and $24 \mathrm{~h}$ after TCV infection at a ratio of 1:1:1:2 was constructed and amplified using the Stratagene Zap cDNA synthesis and cloning kit and the ZAP Express vector (Cooley et al. 2000). The lambda phage cDNA library was converted into a kanamycin-resistant pBK-CMV plasmid library according to the instruction manual (Stratagene). The cDNA library was transformed into $E$. coli XL1-LUX and grown on LC agar plates containing carbenicillin $(100 \mu \mathrm{g} /$ $\mathrm{mL})$, kanamycin $(25 \mu \mathrm{g} / \mathrm{mL})$ and $1 \mathrm{mM}$ IPTG. The cells were incubated at room temperature for 3-4 days and luminescence was recorded using an image scanner. Luminescent clones were streaked onto fresh selected plates. Luminescence was captured after growing at room temperature for another 2-3 days. Plasmids (pBK-CMV and pLUX) were extracted from the $E$. coli colonies with relatively high luminescence and transformed into E. coli XL1-Blue MRF'. The transformants were allowed to grow on LC plates containing carbenicillin $(100 \mu \mathrm{g} / \mathrm{mL})$, kanamycin $(25 \mu \mathrm{g} / \mathrm{mL})$ and $1 \mathrm{mM}$ IPTG at $28^{\circ} \mathrm{C}$ for 1 day, followed by $2-3$ days at room temperature. Subsequently, luminescence was captured using an image scanner.

Single plasmids were isolated from $E$. coli and sequenced. Sequenced plasmids were transformed into E. coli BL21 (DE3) pLysS. The cells were grown in LC medium containing kanamycin $(50 \mu \mathrm{g} / \mathrm{mL})$ and chloramphenicol $(50 \mu \mathrm{g} /$ $\mathrm{mL})$ at $37{ }^{\circ} \mathrm{C}$ until $\mathrm{OD}_{600}=0.6$, induced with $1 \mathrm{mM} \mathrm{IPTG}$ and grown overnight at $18{ }^{\circ} \mathrm{C}$. The cells were collected by centrifugation, resuspended in reaction buffer $(100 \mathrm{mM}$ Tris-HCl pH 7.0, 15 mM MgCl 2,1 mM DTT, 5\% glycerol) and sonicated. Crude soluble cell extracts were obtained after centrifugation. Reaction mixtures $(500 \mu \mathrm{M}$ chorismate, $10 \mu \mathrm{g}$ EntC purified protein, $50 \mu \mathrm{L}$ cell extract) were incubated at $30{ }^{\circ} \mathrm{C}$ for $2 \mathrm{~h}$. Twenty microliters supernatant from the reaction mixtures were mixed with Acinetobacter sp. ADPWH_lux cell culture $\left(\mathrm{OD}_{600}=0.4\right)$ and $50 \mu \mathrm{L} \mathrm{LC}$ medium, incubated at $30{ }^{\circ} \mathrm{C}$ for $1 \mathrm{~h}$. The luminescence was measured using a luminescence counter.

\section{Expression and isolation of recombinant protein}

The full-length coding sequence of PRXR1 was amplified from Arabidopsis cDNA and cloned into pASK-IBA45plus. Recombinant protein was expressed in E. coli strain BL21 (DE3) pLysS and purified with Ni-NTA Agarose (Qiagen) according to the manufacturer's protocol. EntC purification was performed as previous described (Zhou 2018).

Purified protein was dialyzed against buffer containing $100 \mathrm{mM}$ Tris- $\mathrm{HCl} \mathrm{pH} 7.0,15 \mathrm{mM} \mathrm{MgCl}{ }_{2}, 1 \mathrm{mM}$ DTT, 5\% glycerol and stored at $-80{ }^{\circ} \mathrm{C}$. The subunit molecular mass of AtPRXR1 was estimated using 15\% SDS-PAGE. The primers used to amplify AtPRXR1 can be found in Table S2.

\section{Determination of IPL activity}

The IPL reaction was measured by coupling with excess isochorismate synthase (recombinant EntC). In brief, the reaction mixture (500 $\mu \mathrm{M}$ chorismate, $16 \mu \mathrm{g}$ EntC, 3.6-48 $\mu \mathrm{g}$ PRXR1, $100 \mathrm{mM}$ Tris- $\mathrm{HCl} \mathrm{pH}$ 7.0, $15 \mathrm{mM} \mathrm{MgCl} 2,1 \mathrm{mM}$ DTT, 5\% glycerol) in a final volume of $150 \mu \mathrm{L}$ was incubated for $2 \mathrm{~h}$ at $30{ }^{\circ} \mathrm{C}$, vortexed and centrifuged. The supernatant was mixed with Acinetobacter sp. ADPWH_lux cell culture $\left(\mathrm{OD}_{600}=0.4\right)$ and $50 \mu \mathrm{L} \mathrm{LC}$ medium, followed by incubation at $30^{\circ} \mathrm{C}$ for $1 \mathrm{~h}$. The luminescence was measured using a luminescence counter.

Acknowledgements We are grateful to D. Klessig and S. Pathirana for the TCV-induced Arabidopsis cDNA library. This work was supported by a scholarship from the Chinese Scholarship Council (to Y. Z.).

Open Access This article is distributed under the terms of the Creative Commons Attribution 4.0 International License (http://creativeco mmons.org/licenses/by/4.0/), which permits unrestricted use, distribution, and reproduction in any medium, provided you give appropriate credit to the original author(s) and the source, provide a link to the Creative Commons license, and indicate if changes were made.

\section{References}

Ausubel FM, Brent R, Kingston RE, Moore DD, Seidman JG, Smith JA, Struhl K (1987) Current Protocols in Molecular Biology. Greene Publishing Associates/Wiley Interscience, New York

Blazeck J, Alper HS (2013) Promoter engineering: recent advances in controlling transcription at the most fundamental level. Biotechnol J 8:46-58 
Boatwright JL, Pajerowska-Mukhtar K (2013) Salicylic acid: an old hormone up to new tricks. Mol Plant Pathol 14:623-634

Chandra-Shekara AC, Gupte M, Navarre D, Raina S, Raina R, Klessig D, Kachroo P (2006) Light-dependent hypersensitive response and resistance signaling against Turnip Crinkle Virus in Arabidopsis. Plant J 45:320-334

Chong LP, Wang Y, Gad N, Anderson N, Shah B, Zhao R (2015) A highly charged region in the middle domain of plant endoplasmic reticulum (ER)-localized heat-shock protein 90 is required for resistance to tunicamycin or high calcium-induced ER stresses. J Exp Bot 66:113-124

Cooley MB, Pathirana S, Wu H-J, Kachroo P, Klessig DF (2000) Members of the Arabidopsis HRT/RPP8 family of resistance genes confer resistance to both viral and oomycete pathogens. Plant Cell 12:663-676

Cox CD, Rinehart KL, Moore ML, Cook JC (1981) Pyochelin: novel structure of an iron-chelating growth promoter for Pseudomonas aeruginosa. Proc Natl Acad Sci USA 78:4256-4260

Crosa JH, Walsh CT (2002) Genetics and assembly line enzymology of siderophore biosynthesis in bacteria. Microbiol Mol Biol Rev 66:223-249

DeClue MS, Baldridge KK, Kast P, Hilvert D (2006) Experimental and computational investigation of the uncatalyzed rearrangement and elimination reactions of isochorismate. J Am Chem Soc 128:2043-2051

DeFraia CT, Schmelz EA, Mou Z, Cleand C, Ajami A, Shakirova F, Sakhabutdinova A, Bezrukova M, Fatkhutdinova R, Fatkhutdinova $\mathrm{D}$ et al (2008) A rapid biosensor-based method for quantification of free and glucose-conjugated salicylic acid. Plant Methods 4:28

Dempsey DA, Klessig DF (2017) How does the multifaceted plant hormone salicylic acid combat disease in plants and are similar mechanisms utilized in humans? BMC Biol 15:23

Dempsey DA, Pathirana MS, Wobbe KK, Klessig DF (1997) Identification of an Arabidopsis locus required for resistance to turnip crinkle virus. Plant J 11:301-311

Dempsey DA, Vlot AC, Wildermuth MC, Klessig DF (2011) Salicylic acid biosynthesis and metabolism. Arab Book 9:e0156

Dewdney J, Lynne Reuber T, Wildermuth MC, Devoto A, Cui J, Stutius LM, Drummond EP, Ausubel FM (2000) Three unique mutants of Arabidopsis identify eds loci required for limiting growth of a biotrophic fungal pathogen. Plant J 24:205-218

Ding Y, Shaholli D, Mou Z (2014) A large-scale genetic screen for mutants with altered salicylic acid accumulation in Arabidopsis. Front Plant Sci 5:763

Fragnire C, Serrano M, Abou-Mansour E, Métraux JP, L'Haridon F (2011) Salicylic acid and its location in response to biotic and abiotic stress. FEBS Lett 585:1847-1852

Gaille C, Kast P, Dieter H (2002) Salicylate biosynthesis in Pseudomonas aeruginosa. Purification and characterization of $\mathrm{PchB}$, a novel bifunctional enzyme displaying isochorismate pyruvate-lyase and chorismate mutase activities. J Biol Chem 277:21768-21775

Gaille C, Reimmann C, Haas D (2003) Isochorismate synthase (PchA), the first and rate-limiting enzyme in salicylate biosynthesis of Pseudomonas aeruginosa. J Biol Chem 278:16893-16898

Garcion C, Lohmann A, Lamodière E, Catinot J, Buchala A, Doermann P, Métraux J-P (2008) Characterization and biological function of the ISOCHORISMATE SYNTHASE2 gene of Arabidopsis. Plant Physiol 147:1279-1287

Green MR, Sambrook J (2012) Isolating DNA from gram-negative bacteria (e.g., E. coli). Molecular cloning: a laboratory manual, 4th edn. Cold Spring Harb Lab, pp 83-84

Huang WE, Wang H, Zheng H, Huang L, Singer AC, Thompson I, Whiteley AS (2005) Chromosomally located gene fusions constructed in Acinetobacter sp. ADP1 for the environmental detection of salicylate. Environ Microbiol 7:1339-1348
Huang WE, Huang L, Preston GM, Naylor M, Carr JP, Li Y, Singer AC, Whiteley AS, Wang H (2006) Quantitative in situ assay of salicylic acid in tobacco leaves using a genetically modified biosensor strain of Acinetobacter sp. ADP1. Plant J 46:1073-1083

Huang J, Gu M, Lai Z, Fan B, Shi K, Zhou YH, Yu JQ, Chen Z (2010) Functional analysis of the Arabidopsis PAL gene family in plant growth, development, and response to environmental stress. Plant Physiol 153:1526-1538

Inoue H, Nojima H, Okayama H (1990) High efficiency transformation of Escherichia coli with plasmids. Gene 96:23-28

Jha RK, Kern TL, Fox DT, Strauss CEM (2014) Engineering an Acinetobacter regulon for biosensing and high-throughput enzyme screening in $E$. coli via flow cytometry. Nucleic Acids Res 42:8150-8160

Jones RM, Pagmantidis V, Williams PA (2000) sal genes determining the catabolism of salicylate esters are part of a supraoperonic cluster of catabolic genes in Acinetobacter sp. strain ADP1. J Bacteriol 182:2018-2025

Kachroo P, Yoshioka K, Shah J, Dooner HK, Klessig DF (2000) Resistance to turnip crinkle virus in Arabidopsis is regulated by two host genes and is salicylic acid dependent but NPR1, ethylene, and jasmonate independent. Plant Cell 12:677-690

Kerbarh O, Ciulli A, Howard NI, Abell C (2005) Salicylate biosynthesis: Overexpression, purification, and characterization of Irp9, a bifunctional salicylate synthase from Yersinia enterocolitica. J Bacteriol 187:5061-5066

Luo Q, Meneely KM, Lamb AL (2011) Entropic and enthalpic components of catalysis in the mutase and lyase activities of pseudomonas aeruginosa PchB. J Am Chem Soc 133:7229-7233

Macaulay KM, Heath GA, Ciulli A, Murphy AM, Abell C, Carr JP, Smith AG (2017) The biochemical properties of the two Arabidopsis thaliana isochorismate synthases. Biochem $\mathrm{J}$ 474:1579-1590

Mercado-Blanco J, van der Drift KM, Olsson PE, Thomas-Oates JE, van Loon LC, Bakker PA (2001) Analysis of the pmsCEAB gene cluster involved in biosynthesis of salicylic acid and the siderophore pseudomonine in the biocontrol strain Pseudomonas fluorescens WCS374. J Bacteriol 183:1909-1920

Nawrath C, Métraux JP (1999) Salicylic acid induction-deficient mutants of Arabidopsis express PR-2 and PR-5 and accumulate high levels of camalexin after pathogen inoculation. Plant Cell 11:1393-1404

Nawrath C, Heck S, Parinthawong N, Métraux JP (2002) EDS5, an essential component of salicylic acid-dependent signaling for disease resistance in Arabidopsis, is a member of the MATE transporter family. Plant Cell 14:275-286

Ozenberger BA, Brickman TJ, McIntosh MA (1989) Nucleotide sequence of Escherichia coli isochorismate synthetase gene entC and evolutionary relationship of isochorismate synthetase and other chorismate-utilizing enzymes. J Bacteriol 171:775-783

Park HH, Lee HY, Lim WK, Shin HJ (2005) NahR: effects of replacements at Asn 169 and Arg 248 on promoter binding and inducer recognition. Arch Biochem Biophys 434:67-74

Passardi F, Penel C, Dunand C (2004) Performing the paradoxical: how plant peroxidases modify the cell wall. Trends Plant Sci 9:534-540

Pelludat C, Brem D (2003) Irp9, encoded by the high-pathogenicity island of Yersinia enterocolitica, is Able to convert chorismate into salicylate, the precursor of the siderophore Yersiniabactin. J Bacteriol 185:5648-5653

Rivas-San Vicente M, Plasencia J (2011) Salicylic acid beyond defence: its role in plant growth and development. J Exp Bot 62:3321-3338

Ruiz-Duenas FJ, Chau TAL, Perez-Boada M, Martinez MJ, Martinez AT (2001) Heterologous expression of a ligninolytic versatile peroxidase from Pleurotus eryngii in Aspergillus species. J Inorg Biochem 86:411 
Schell MA (1993) Molecular biology of the LysR family of transcriptional regulators. Annu Rev Microbiol 47:597-626

Serrano M, Wang B, Aryal B, Garcion C, Abou-Mansour E, Heck S, Geisler M, Mauch F, Nawrath C, Metraux JP (2013) Export of salicylic acid from the chloroplast requires the multidrug and toxin extrusion-like transporter EDS5. Plant Physiol 162:1815-1821

Shin HJ (2010) Development of highly-sensitive microbial biosensors by mutation of the nahR regulatory gene. J Biotechnol 150:246-250

Shine MB, Yang JW, El-Habbak M, Nagyabhyru P, Fu DQ, Navarre D, Ghabrial S, Kachroo P, Kachroo A (2016) Cooperative functioning between phenylalanine ammonia lyase and isochorismate synthase activities contributes to salicylic acid biosynthesis in soybean. New Phytol 212:627-636

Spoel SH, Dong X (2012) How do plants achieve immunity? Defence without specialized immune cells. Nat Rev Immunol 12:89-100

Strawn MA, Marr SK, Inoue K, Inada N, Zubieta C, Wildermuth MC (2007) Arabidopsis isochorismate synthase functional in pathogen-induced salicylate biosynthesis exhibits properties consistent with a role in diverse stress responses. J Biol Chem 282:5919-5933

Uknes S, Winter AM, Delaney T, Vernooij B, Morse A, Friedrich L, Nye G, Potter S, Ward E, Ryals J (1993) Biological induction of systemic acquired resistance in Arabidopsis. Mol Plant Microbe Interact 6:692-698

Verberne MC, Verpoorte R, Bol JF, Mercado-Blanco J, Linthorst HJM (2000) Overproduction of salicylic acid in plants by bacterial transgenes enhances pathogen resistance. Nat Biotechnol 18:779-783

Walsh CT, Liu J, Rusnak F, Sakaitani M (1990) Molecular studies on enzymes in chorismate metabolism and the enterobactin biosynthetic pathway. Chem Rev 90:1105-1129
Welinder KG, Mauro JM, Norskovlauritsen L (1992) Structure of plant and fungal peroxidases. Biochem Soc Trans 20:337-340

Wildermuth MC, Dewdney J, Wu G, Ausubel FM (2001) Isochorismate synthase is required to synthesize salicylic acid for plant defence. Nature 414:562-565

Winson MK, Swift S, Fish L, Throup JP, JÃ, rgensen F, Chhabra SR, Bycroft BW, Williams P, Stewart GSAB. (1998a) Construction and analysis of luxCDABE -based plasmid sensors for investigating $N$-acyl homoserine lactone-mediated quorum sensing. FEMS Microbiol Lett 163:185-192

Winson MK, Swift S, Hill PJ, Sims CM, Griesmayr G, Bycroft BW, Williams P, Stewart GSAB. (1998b) Engineering the luxCDABE genes from Photorhabdus luminescens to provide a bioluminescent reporter for constitutive and promoter probe plasmids and mini-Tn5 constructs. FEMS Microbiol Lett 163:193-202

Yamasaki K, Motomura Y, Yagi Y, Nomura H, Kikuchi S, Nakai M, Shiina T (2013) Chloroplast envelope localization of EDS5, an essential factor for salicylic acid biosynthesis in Arabidopsis thaliana. Plant Signal Behav 8:e23603

Zhang D, Zhao Y, He Y, Wang Y, Zhao Y, Zheng Y, Wei X, Zhang L, Li Y, Jin T et al (2012) Characterization and modeling of transcriptional cross-regulation in acinetobacter baylyi ADP1. ACS Synth Biol 1:274-283

Zhou Y (2018) Exploring novel regulators and enzymes in salicylic acid-mediated plant defense. $\mathrm{PhD}$ thesis, Leiden

Zwahlen J, Kolappan S, Zhou R, Kisker C, Tonge PJ (2007) Structure and mechanism of MbtI, the salicylate synthase from Mycobacterium tuberculosis. Biochemistry 46:954-964 